\title{
FONTES CLÍNICAS, HISTÓRIA DA LOUCURA E HISTÓRIA DA PSIQUIATRIA: UMA REVISÃO HISTORIOGRÁFICA
}

\author{
PSYCHIATRIC CASE RECORDS, HISTORY OF MADNESS AND \\ HISTORY OF PSYCHIATRY: A HISTORIOGRAPHICAL REVIEW
}

\begin{abstract}
Allister Dias ${ }^{1}$
RESUMO: Registros clínico-psiquiátricos vêm sendo explorados como fontes históricas por diversos historiadores e cientistas sociais interessados em compreender as transformação dos saberes e práticas médico-psicológicas. Da mesma maneira, tais testemunhos históricos vêm revelando imensa potencialidade heurística na reconstrução das variadas e complexas experiências da loucura, nos mais diversos espaços e tempos. Este artigo traça um balanço historiográfico com atenção voltada à literatura da história da psiquiatria e da loucura em âmbito internacional e nacional que fez uso deste tipo documental. Demarcamos, como conclusão, o quanto a mobilização de tais fontes contribui para a relativização de interpretações de cunho funcionalista da história dos saberes médico-psicológicos e da loucura.
\end{abstract}

PALAVRAS-CHAVE: história da psiquiatria, fontes históricas, historiografia, loucura, controle social

ABSTRACT: Psychiatric case records have been explored as historical sources by several historians and social scientists interested in understanding the transformation of medical-psychological knowledge and practices. In the same way, such historical testimonies have revealed immense heuristic potentiality in the reconstruction of the varied and complex experiences of madness, in the most diverse spaces and times. This contribution will draw a historiographic review with attention to the literature on the history of psychiatry and madness at the international and national level that made use of this documentation. We point out, in conclusion, how the use of such sources tends to relativize functionalist interpretations of the history of madness and medicalpsychological knowledge.

KEYWORDS: history of psychiatry; historical sources; historiography; madness; social control

\footnotetext{
* Pesquisa decorrente do projeto de pesquisa "Do Hospício de Pedro II ao Hospital Nacional de Alienados: cem anos de histórias (1841-1944)" (CNPq/Casa de Oswaldo Cruz), desenvolvido na Fundação Oswaldo Cruz, com financiamento do CNPq/COC.

1 Historiador. Doutor em História das Ciências pela Fundação Oswaldo Cruz, com pósdoutorado na mesma instituição. Atualmente Pesquisador Bolsista PNP da Fundação Biblioteca Nacional.
} 


\section{Introdução}

Como bem conhecido no campo da história, é a reflexão crítica sistemática de historiadores e cientistas sociais em relação aos testemunhos e registros da atividade humana, escritos ou não, que faz destes, em sua pluralidade, fontes para o conhecimento histórico. Mediadas pela linguagem, tais fontes constituem a matéria prima de onde se extraem indícios do "presente das necessidades práticas onde os atores do passado se encontravam" (POCOCK, 2003, p.38).

Quando se fala de documentação clínica psiquiátrica - ou registros de casos clínicos psiquiátricos - de forma geral, refere-se à documentação escrita muitas vezes também fotográfica - que conta a história social, familiar e médica de um paciente internado em instituições psiquiátricas (ARCHIBAL, 2013, p.102-104). Circunscrevemos, aqui, como fontes clínicas psiquiátricas, livros e dossiês de observação, livros de entrada e saída e laudos psiquiátricos forenses de pacientes que passaram por instituições psiquiátricas.

Com total certeza, tendo em mente o conjunto da historiografia da psiquiatria ao menos desde os anos setenta para cá, está documentação não predomina como corpus documental dos principais trabalhos na área. $\mathrm{O}$ campo de imersão é extenso, porém, aqui neste artigo se trata de um exercicío exploratório absolutamente viável que servirá de mapa orientador para pesquisas futuras. A seleção de estudos aqui abordados, tanto os nacionais quanto os internacionais, é parcial, não poderia deixar de ser; mas as investigações abordadas sintetizam no seu conteúdo e preocupações as principais questões que análises que se propoem a destrinchar fontes clínicas enfrentam. Daí figurarem nesse balanço. Para além disso, este artigo decorre das reflexões provenientes de uma disciplina ofertada por mim e outras professoras em Programa de pós-graduação em história sobre história da psiquiatria e suas instituições. Desse modo, diz respeito a literatura nacional e internacional (em especial em línguas inglesa, espanhola e francesa, mais lidas aqui) acessível e reconhecidamente de mais relevo. 
Na historiografia norte-americana e inglesa este tipo de documentação é chamada de case records, clinical records. Já a ibero-americana a trata por relatos patográficos, historias clinicas, expedientes clinicos, ou mesmo fuentes clinicas. Para produzir seus conhecimentos próprios e particulares, a psiquiatria necessita construir material empírico. Seu material empírico são esses casos, essas histórias clínicas: testemunhos deixados pela prática psiquiátrica.

Os laudos periciais, tipo de relato mais denso, são fontes não só para o estudo da história da psiquiatria e da loucura, mas também da medicina legal, da psiquiatria forense, da criminologia, do direito penal, da prática policial, do crime, etc. Tendem a conter em si vários discursos: psiquiátrico, policial, jurídico, do paciente, de familiares e de outros atores, trazendo embutidos fragmentos de outros documentos - autos policiais, decisões jurisprudências, cartas ou depoimentos de acusados, familiares, etc. Estes laudos no geral estão presentes nos arquivos dos antigos manicômios judiciários (DUMOLIN, 2000). 2

De maneira geral, tais registros clínicos trazem consigo um conjunto complexo de dificuldades e potencialidades para o historiador. As dificuldades de ordem legal são bem conhecidas, tendo em vista que se trata de documentação que contém informações de caráter sigiloso, pessoal e privado. $\mathrm{O}$ acesso a este tipo de documentação, em boa parte do mundo ocidental, é pautado pelos princípios da privacidade e confidencialidade. No geral, as pesquisas que as têm como escopo são obrigadas a passar por comitês de ética em pesquisa, cujo norteamento, ao menos no Brasil, se dá por critérios vindos do campo disciplinar da bioética, sem levar em consideração as particularidades das ciências humanas (EDLE, 2015).

O fato é que há uma imensa variedade de condições de acesso, status legal e disponibilidade para consulta de tais fontes. Preservação, estado de conservação e possibilidades de acesso constituem outros problemas a serem

\footnotetext{
2 A destinação da documentação clínica dos antigos MJs no Brasil é variada. Ora pertencem a arquivos públicos estaduais (casos de São Paulo e Minas), ora às instituições que substituíram tais MJs (Hospitais de Custódia, Institutos de Perícia, ou Museu Penitenciário, como no caso do Rio de Janeiro).
} 
levados em conta. No Brasil, a maior parte das instituições psiquiátricas públicas mais antigas - como o Juquery em São Paulo, o Hospital Nacional de Alienados, no Rio de Janeiro, etc- não preservou a totalidade de sua documentação clínica, e sua organização foi e tem sido complicada. Pesquisas têm se obrigado a se debruçar em quantitativos parciais, o que, sem a devida atenção dos pesquisadores, pode engendrar equívocos de interpretação significativos. Em alguns casos, as(os) historiadoras(es) foram verdadeiras(os) desbravadoras(es) no descobrimento de documentação (CUNHA, 1986; WADI, 2002).

Além disso, este tipo de documentação tende a não apresentar homogeneidade no seu conteúdo, estando sempre suscetível às idiossincrasias das instituições produtoras e dos responsáveis por seu preenchimento. Sobreviveram ao tempo, todavia, observações clínicas bem completas, repletas de informações, tanto sobre os indivíduos internados, quanto acerca das concepções e práticas dos operadores do saber psiquiátrico - psiquiatras, médicos internos, enfermeiros, etc. - e das práticas institucionais cotidianas. Observações clínicas completas permitem ao pesquisador acessar, ainda que parcialmente e sem a ilusão de alcance de um suposto real ou a verdade do que "de fato aconteceu", microdinâmicas institucionais, relações intersubjetivas e representações sociais. Desta forma, os registros clínicos podem se transformar em janelas interessantes para a leitura das sensibilidades e das construções de subjetividades de um tempo e lugar (NOVELLA, 2009).

Há, entretanto, as que são somente "fragmentos de trajetórias anônimas" (SALLA; BORGES, 2017, p.116), registros de poucas linhas. É importante que fique claro ao leitor e estudioso: na maior parte das vezes há sérios limites na reconstrução de experiências de internamento a partir destas fontes. O que não significa que estas lacunas não possam ser preenchidas pelo feixe de outros vestígios. 
História das práticas psiquiátricas e a história da loucura "vista de baixo"3

De forma esquemática, pode-se dizer que as tradições historiográficas que têm a loucura e a psiquiatria como objeto se dividem em duas grandes vertentes interpretativas: uma historiografia "whig", ou tradicional, e uma "historiografia revisionista" ou "crítica", ambas, no entanto, abrangendo uma pluralidade de enfoques.

A historiografia "whiggista" da psiquiatria tende a pensar a ciência e a assistência psiquiátrica de forma evolutiva e teleológica. Desenvolvida principalmente por psiquiatras, psicólogos ou psicanalistas, esta tradição historiográfica se voltou para a legitimação profissional e epistemológica da área de conhecimento ${ }^{4}$. Por sua vez, a historiografia revisionista ou crítica, desenvolvida a partir dos anos sessenta e sob influência dos trabalhos Michel Foucault, Thomas Szas, Erving Goffman, e do movimento antipsiquiátrico de forma geral, introduziu uma interpretação da psiquiatria e das suas instituições a partir do conceito de controle social e do entendimento da loucura como "construção social”. Na linguagem da história das ciências, seriam abordagens "externalistas", pautadas na ênfase das "sobredeterminações de cunho estruturalista” (EDLER, 2011, p.199).

Estas histórias whiggistas ou críticas, a despeito de seus méritos e limites impostos pelos regimes de historicidade e cultura de pesquisa histórica nos quais se inscreviam (PORTER e MICALE, 1994) pouco complexificaram as escolhas epistêmicas e assistenciais da psiquiatria em perspectiva diacronica, ou mesmo pouco olharam mais de perto, por meio de investigação empírica, suas práticas. Nesse sentido, até o final dos anos 1970, estudar sistematicamente registros clínicos para produzir conhecimento histórico sobre os saberes

\footnotetext{
${ }^{3}$ No espaço de um artigo de 20 páginas não é possível destrinchar analiticamente o conteúdo de cada obra. Tecemos aqui reflexões que buscam condensar as principais questões legadas pelos estudos em tela.

${ }^{4}$ Para um destrinchamento da conhecida historiografia chamada "whiggista", conferir Porter e Micale (1994). Para o caso do "whiggismo" em história da psiquiatria no Brasil ver Facchinetti e Venâncio (2018).
} 
médico-psicológicos, ou sobre as apreensões sociais da "loucura", não estava no horizonte.

Porém, o final dos anos sessenta já assiste ao surgimento de abordagens de cunho mais histórico-sociológico, no que pode ser considerada uma “sociologia histórica da doença mental”. George Rosen (1968) destrinchou os processos socioculturais de estabelecimento de consensos para a definição da condição de doente mental e de sua marginalização. Trazendo como importantes para este processo elementos como classe social, raça e gênero, foi pioneiro em inscrever a categorização de doença mental nas estruturas sociais, econômicas e culturais. Trabalhos posteriores, embasados no estudo empírico de fontes clínicas, nos anos oitenta e noventa, darão mais concretude à relação psiquiatria/loucura e sociedade.

Entre o início dos anos 1970 e fins dos anos 1980 apareceram quatro estudos que começaram a matizar e enriquecer a perspectiva crítica a partir de preceitos teóricos, conceituais e metodológicos provenientes da sociologia, da história social, da história e sociologia das profissões, da história das ideias e da história da medicina ${ }^{5}$. São eles: Museum of Madness. The Social Organization of Insanity in Nineteenth Century England, do sociólogo Andrew Scull (1979); Console e Classification. The French Psychiatric Profession in the nineteenth century, da historiadora Jan Goldstein (1987); La chronicité dans la psychiatrie moderne française, do psicanalista Lanteri-Laura (1972), publicado na revista dos Annales; e A Social History of Madness, do historiador Roy Porter (1987).

Lanteri-Laura (1972) foi pioneiro em destrinchar as transformações epistemológicas da psiquiatria francesa que levaram à consolidação da

\footnotetext{
${ }^{5}$ Importante demarcar que aqui figuram estudos que partem do campo da história e que abrem o terreno para estudos que mobilizam a documentação clínica. É bem sabido que Foucault em Folie et Derasion inaugura a historicização da loucura como artefato cultural, fazendo uma primorosa história da razão e sua cisão com a desrazação, considerada pelos Annales (Braudel e Chaunnu, por exemplo) como um grande trabalho de história das mentalidades. Porém não caberia nesta análise. Por sua vez, o trabalho de Robert Castel, A ordem psiquiátrica, traduz um esforço de encaixe do saber psiquiátrico na dinâmica política da França da primeira metade do oitocentos, reforçando os argumentos da historiografia crítica e da chamada tese do controle social em história da psiquiatria. No entanto, não enseja questões pertinentes a nossa preocupação neste texto, que não é um balanço historiográfico do historiar da psiquiatria, mas dos estudos que mobilizaram fontes clínicas e daqueles, anteriores, que se constituíram em condição de possibilidade para tal.
} 
"cronicidade" e do "somaticismo" na compreensão das doenças mentais, levando a um cada vez maior abandono dos projetos terapêuticos de fins do setecentos e início do oitocentos e à hipertrofia da função administrativa/custodiadora da psiquiatria e suas instituições. O trabalho de Scull, na linha Rosen, representou uma guinada mais consolidada rumo a uma sociologia histórica da psiquiatria e da loucura, com maior base empírica. No livro em questão, Scull buscou mostrar os significados culturais da loucura e a estruturação institucional da psiquiatria na Inglaterra do século XIX. Já Goldstein percorreu o itinerário da profissionalização do alienismo francês no século XIX, enfatizando o quanto o aprimoramento do corpus de conhecimento psiquiátrico atuou neste percurso e na aproximação deste saber-poder com as ideologias políticas liberais.

Por sua vez, Roy Porter, antes mesmo do seu A social history of madness, em artigo de 1985, enfatizou a necessidade do estudo do "ponto de vista do paciente" e, consequentemente, das experiências e cotidiano dos internamentos. Segundo Porter, ao interpretar a formação da classe operária inglesa, Thompson

Alertou-nos da super rígida e mecanicista visão das relações de classe, argumentando que as classes não são estruturas ou fatos estáticos, mas um fluido e dinâmico processo, e construção e reconstrução ao longo do tempo. O paralelo com a relação dos pacientes com a medicina é pertinente. Uma história das pessoas que foram pacientes deve recuperar para a história da medicina sua face humana (PORTER, 1985, p.194).

A relevância do paciente na história da medicina seria equivalente à importância e protagonismo que a nova história social atribuiu aos segmentos subalternos neste período. Ou seja, Porter propugnava, em meados dos anos oitenta, cuidados e diretrizes metodológicas para compreensão da relação médico-paciente em períodos passados, entre elas: atentar para experiências de adoecimento diferentes das nossas; repensar o papel das famílias e comunidades nas experiências de adoecimento; compreender que os "pacientes" ao longo da história iniciavam seus tratamentos antes de interação com o médico; por fim, que, sob a medicina, os pacientes não são passivos. Porter conclama uma 
guinada antropológica em direção ao "outro", ao doente do passado relativizando a "teoria da medicalização".

Poucos anos depois, Porter retoma estas assunções. Para o autor, os delírios dos pacientes, as ideias psiquiátricas e os discursos sociais estariam dentro de um "tecido ideológico comum" (PORTER, 1987, p.16). Na linha de Scull e Rosen, dando voz a alguns pacientes psiquiátricos "célebres", enfatizou que o "entorno social" ajudaria a emoldurar as diferentes categorias diagnósticas entendidas culturalmente como "loucura". Essas ideias se converteram em pressupostos fundamentais que foram absorvidos por historiadores e cientistas sociais interessados no tema ao longo dos anos 1990. As reflexões de Porter e dos outros autores mencionados firmaram abordagens históricas de enfoque sociocultural, socioprofissional e sociocognitivo na história da loucura e da psiquiatria.

Paulatinamente ganhou cada vez mais relevância, como objeto, a prática psiquiátrica na sua operação mais concreta e suas relações com a experiência de indivíduos submetidos a rótulos diagnósticos variados no interior de instituições manicomiais. Isso somado ao impacto das propositivas provenientes da nova história cultural, das várias abordagens da história intelectual, da história das ciências e dos estudos de gênero. O interesse cada vez maior nos expedientes clínicos se situa nessa atmosfera intelectual dos anos 1980 e 1990, juntando-se a isso o processo político de luta pela cidadanização dos portadores de sofrimento psíquico.

Nos anos 1980, 1990 e 2000, o estudo da documentação clínica em âmbito internacional tendeu ora a relativizar as assertivas da historiografia crítica, ora a corroborá-las. Se o discurso dos psiquiatras, nos seus textos, permitia ver suas retóricas e racionalidades em defesa de certas categorias diagnósticas, modelos de política assistencial e mesmo estratégias de afirmação profissional e controvérsias variadas, a cotidianidade da prática psiquiátrica escapava ao olhar do historiador. As fontes clínicas apareceram então como fontes que "transcendiam o discurso do especialista" (HUERTAS, 2013, p.9). A partir delas, alguns pesquisadores começaram a estudar a práxis psiquiátrica 
tentando perceber as ambiguidades da relação teoria-prática e as experiências da loucura em tempos e espaços específicos. Vejamos alguns exemplos na historiografia europeia, primeiramente.

$\mathrm{Na}$ historiografia anglo-americana se notabilizaram trabalhos de história social e institucional que mobilizaram documentos de natureza clínica. O protagonismo das famílias e de outros atores, como polícia e justiça, nas internações tem sido destacado, redimensionando o poder psiquiátrico. Allan Beveridge (1995), em estudo sobre o Royal Edinburgh Asylum, de 1873 até 1906, por meio dos expedientes clínicos, percebeu o quanto as famílias das regiões rurais eram mais reticentes em internar seus "loucos" do que a população urbana, mantendo uma percepção e um trato cultural diferente da questão, no que chamou de uma "gestão vicinal e familiar da loucura" (HUERTAS, 2012, p.152).

Para o caso da França, a historiadora Patricia Prestwich (2003a) estudou, por meio de informações constantes em sete mil dossiês de internação do asilo de Sainte-Anne, Paris, entre 1873 e 1913, as demandas sociais na definição das internações psiquiátricas. Para Prestwich, os asylum records eram a única documentação capaz de ajudar a compreender os motivos da internação psiquiátrica e, assim, a entender as características que aquela instituição assumiu. O estudo dos internamentos "voluntários", a partir dos registros clínicos, contribuiu para a compreensão do "emaranhado de razões" que levam uma família a internar um parente, no geral fugidias ao historiador. $\mathrm{O}$ estudo mostrou o protagonismo das famílias, suas elaborações de sentidos acerca da instituição e suas formas de tratamento. Não se pode falar, para a realidade de Paris do período, de abandono total dos pacientes, ou mesmo de exclusão das famílias com relação ao tratamento dos seus parentes. Sem contar a tramas familiares que estas fontes potencialmente revelam. O certo é que a historiadora demonstra bem os intercâmbios e as disputas entre concepções de loucura e cura entre médicos e famílias. É um caso, como outros, em que a instituição psiquiátrica reflete as respostas dos grupos sociais e das famílias à loucura. 
Tais fontes mostram potencialmente bem o perfil dos pacientes. Como veremos, a categoria gênero ganhou muito importância no estudo histórico da loucura e da psiquiatria nos últimos trinta anos. Para Prestwich (2003b), em estudo sobre o alcoolismo feminino a partir de fontes clínicas, gênero seria uma a categoria mais explicativa que os diagnósticos distinção dos pacientes e das diferentes experiências de internamento.

Nos seus estudos sobre o hospital psiquiátrico Wittenauer Heilsttaten, de Berlin, entre 1919 e 1960, Andrea Dörries e Thomas Beddies (2003), basearam-se em registros clínicos de 4 mil pacientes - de uma seleção representativa dos 50 mil registros clínicos relativos ao período. Mostraram como a realidade asilar de uma instituição psiquiátrica típica, centralizadora, de caráter fechado e voltada para as camadas pobres, operou em três sistemas políticos - Weimar, o Nazismo e a Western German Democracy. No final do período de Weimar, em meio à crise econômica, as condições de vida para os pacientes psiquiátricos ficaram terríveis. Aí se gestaram as condições para os discursos nazistas de esterilização e dizimação de parte da população psiquiátrica. Este momento gerou uma atmosfera de "fazer crer que os 'inferiores' deveriam ter menos liberdades que as pessoas do lado de fora, que eram saudáveis e estavam em condições de trabalhar" (DÖRRIES e BEDDIES, 2003, p.155). Os autores elaboraram complexas estatísticas em suas análises, chegando a alguns nós analíticos: perfil heterogêneo dos pacientes; porcentagem de mortes muito alta; tendência de crescimento do número de mulheres de idade mais avançada, no geral sozinhas e dos extratos menos favorecidos da sociedade berlinense no pós guerra.

Muitos estudos vêm enfatizando o quanto desta documentação clínica se decanta uma prática psiquiátrica modulada culturalmente, sobretudo pelas dimensões de classe e gênero. É por meio destas modulações que tal prática opera as delimitações entre normal, diferente e anormal. Nesta chave, o enfoque de gênero adentrou de forma significativa o campo da história da psiquiatria e da loucura com muitos trabalhos que recorreram sistematicamente à documentação clínica para relativizar teses "clássicas". 
A chamada "história feminista da psiquiatria" (TOMES, 1994) tem ora enxergado a prática psiquiátrica como mais coercitiva com relação às mulheres (tese "assimétrica"), como o estudo de Elaine Showalter (1987), ora visto, numa perspectiva de gênero mais relacional, ou "simétrica", a prática psiquiátrica construindo linguagens "generificadas" (gendered) e definições normativas tanto de feminilidade quanto de masculinidade (COLEBORNE, 2014).

O século XIX tem sido mais explorado nesses estudos com viés de gênero. Ann Goldberg (1998) se debruçou sobre os case records de pacientes "ninfomaníacas" do hospital psiquiátrico Eberbach, o primeiro asilo de alienados da Alemanha, na primeira metade do XIX. Goldberg demonstrou o quanto a ninfomania como rotulação diagnóstica envolveu significativos pressupostos de classe (mulheres do mundo rural, pobres) e gênero. Catherine Coleborne (2014) estudou os homens internados em asilos na Austrália e na Nova Zelândia na segunda metade do século XIX, a partir de seus registros clínicos (4000 cases records). Em contexto colonial muitos padrões para o "homem branco" advinham da linguagem médico-institucional. A masculinidade do "homem branco colonial" era exacerbada, "desbravadora", "rude", "independente", violenta e competitiva; contrastando com a masculinidade racional e controlada dos psiquiatras, europeus de nascimento. Para estes, a "paralisia geral progressiva" (condição derivada da sífilis) aparecia como marca do homem colonial, tendente ao sexo fora do casamento. Para estes homens a domesticidade e o casamento teriam componentes higiênicos importantes, na ótica médica.

Hilary Marland (2012), na linha do estudo da experiência do internamento de mulheres, realizou estudos sobre mulheres diagnosticadas com "loucura puerperal" (pós-parto) na Inglaterra do século XIX e início do século XX. Utilizando-se dos case notes e textos médicos para reconstruir a forma como as mulheres traduziam seus sofrimentos, percebeu no discurso das pacientes uma associação forte entre parto, sofrimento, terror e morte. Para ela,

Estes casos clínicos vão além da descrição da doença mental como aparecem em textos médicos, jurídicos e literários, 
reportando uma experiência dos médicos na prática e na linha de frente da regulação dos diagnósticos e tratamentos, sendo de considerável valor para os historiadores da psiquiatria. (MARLAND, 2012, p.317)

É neste tipo de documentação que, para a autora, estão melhor delineadas as explicações para o adoecimento psíquico, tanto por parte dos médicos, quanto das próprias pacientes. Nos casos de loucura puerperal, fatores como pobreza, exaustão física, violência doméstica, etc., são recorrentemente acionados por médicos e pacientes. Seu diálogo primacial é com a tese de Showalter, interpretação que, para Marland, reduziu o espaço asilar a um microcosmo da "guerra dos sexos". As fontes clínicas demonstraram, por seu turno, a existência de diversas percepções da loucura na Inglaterra vitoriana, não só ligadas à ideia de "mulheres desviantes". Tal documentação abriu um mundo de formulações etiológicas complexas, caso a caso, mostrando a face terapêutica da psiquiatria e redimensionando o lugar do hospício, muitas vezes o único lugar possível de descanso e alimentação para mulheres esgotadas pelas condições degradantes do trabalho fabril, num momento de auge da $1^{\circ}$ Revolução Industrial.

Nos últimos vinte anos, os estudos das sensibilidades da experiência de internamento psiquiátrico ganharam espaço. Utilizando-se de fontes clínicas e de outras naturezas, historiadores mexicanos como Andrés Molina (2009) e Cristina Rivera-Garza (2011), estudando a história do Manicomio General de la Castaneda, no México, investigaram a experiência do internamento na perspectiva do interno. Tais fontes ajudaram estes historiadores a repensar a natureza destas instituições, pintando - ao menos para o período abarcado por estes estudos, no geral da criação da instituição no início do século XX até a década de 1950 - retratos não de "laboratórios" racionalizados, ou "instituições totais" guiadas por um poder psiquiátrico; mas instituições "camaleônicas", complexas, atravessadas por várias dinâmicas: de disciplinamento, confinamento e repressão, mas também de terapêutica e cuidado.

Pensar a história da instituição por meio de seus expedientes clínicos, "fontes históricas polifônicas" (MOLINA, 2009, p.37), e, portanto, da 
experiência de seus protagonistas, principalmente psiquiatras e pacientes, abre significativas possibilidades interpretativas. Para Molina, "o olhar do historiador deve ir além da dinâmica da instituição ou das reformas administrativas, instrumentalizadas pelas diretrizes de cada conjuntura política" (MOLINA, p.41). A realidade da "modernidade psiquiátrica" vai muito além desses aspectos, e deve ser visualizada no cotidiano e nas experiências da "loucura" no interior das instituições.

A narrativa clínica condensa em si vestígios ambíguos dos sujeitos submetidos à situação de internamento. Como apontou a também historiadora mexicana Cristina Sacristán,

Interpretando estas fontes a partir dos seus contextos podemos encontrar as ideias, as expectativas, as queixas, os sofrimentos e os temores, não só dos que chamamos de loucos, mas também dos seus próprios contemporâneos, porque fazem referência a uma realidade existente e compartilhada (SACRISTÁN, 2005, p.680).

Por outro lado, algo fundamental da polifonia destes registros diz respeito aos documentos anexos que eles podem vir a trazer, principalmente aqueles produzidos pelos próprios pacientes, como cartas e escritos diversos, ou ainda, recortes de jornais anexados pelos próprios psiquiatras em casos nos quais a vida ou os atos do internado ganharam repercussão pública. Para Molina, as cartas de pacientes psiquiátricos redimensionam, a partir de outras perspectivas, o cotidiano de reclusão e suas relações de poder, os "códigos que regiam a comunicação entre pacientes e médicos, a experiência subjetiva do interno, sua atitude diante da instituição psiquiátrica, ao tratamento e ao diagnóstico" (MOLINA, 2009, p.74). Auscultar a fala do "louco" por suas cartas, como se estas sintetizassem a subjetividade do mesmo em "estado de pureza" (MOLINA, p.75), é, no entanto, ingênuo.

A perspectiva diacrónica de análise dessas fontes tem ajudado a perceber lentas ou abruptas transformações nos modelos diagnósticos e terapêuticos. O estudo histórico das terapêuticas psiquiátricas, por exemplo, com ênfase nas terapias biológicas, como a hidroterapia, a esterilização, as cirurgias sexuais, a terapia de febre malárica, a lobotomia e a 
psicofarmacologia, tem se desenvolvido bastante com o uso de fontes clínicas. Para Andrew Scull, ainda que com muitas limitações, elas ajudam a inserir a história da psiquiatria na história da medicina, permitindo o acompanhamento das indissociáveis compreensões médicas das doenças e das terapêuticas. Contribuem também para a compreensão dos "usos e implementações" de abordagens terapêuticas em "cenários clínicos específicos, ao invés de ter em conta somente as afirmações presentes em publicações da literatura profissional" (SCULL, 2006, p.17).

No que diz respeito as suas aplicações em função de assunções de gênero, merece destaque os trabalhos de Joel Braslow (1997) e sua manipulação quantitativa e qualitativa da documentação clínica de hospitais psiquiátricos norte-americanos por boa parte do século XX. A partir da interpretação sistemática dos patient medical records, Braslow demonstrou a implantação de uma racionalidade terapêutica fisicalista - intervir no corpo como caminho para atingir a mente e o comportamento - na psiquiatria, voltada para o controle comportamental. Aponta, ainda, para como as expectativas de gênero moldaram os critérios de adoção de terapias biológicas, mais especificamente a inclinação psiquiátrica, naquele contexto institucional, a lobotomizar mais as mulheres do que os homens, em função das consequências comportamentais desta brutal intervenção física.

A historiografia brasileira segue algumas das linhas tendenciais descritas acima, mas com particularidades relevantes, muitas vezes com pioneirismo.

A prática psiquiátrica e o ponto de vista do paciente nos estudos brasileiros

O livro O espelho do mundo. Juquery, a história de um asilo, de Maria Clementina da Cunha, marca o início do interesse mais significativo do universo historiográfico brasileiro na temática da história da loucura e da 
psiquiatria $^{6}$. Já em 1986, em investigação de fôlego, Cunha (1986) explorou cuidadosamente milhares de observações de pacientes internados no hospício do Juquery, Campinas-São Paulo, entre fins do século XIX e meados do século $\mathrm{XX}$. Procurou entender de que maneiras o espaço asilar refletia as desigualdades sociais, raciais e de gênero próprios da sociedade brasileira. Querendo dar voz aos pacientes e revelar a experiência do internamento (“carreira asilar"), interpretou pequenos fragmentos de resistência ao poder psiquiátrico na documentação. Para a historiadora, a documentação clínica, como fonte histórica rica, constituiu, na sua pesquisa, a única janela para "descer à abordagem dos casos", das histórias de vida e experiências individuais (CUNHA, 1986, p.114 e 121).

Na esteira de Cunha, a historiadora Magali Engel (2001), em Delírios da razão: médicos, loucos e hospícios no Rio de Janeiro (1830-1930), também fez uma ampla e profunda reflexão, utilizando-se de alguns tipos de documentação clínica. De forma menos sistemática que Cunha, todavia, debruçou-se sobre os influxos socioculturais que atuaram no saber e na prática psiquiátrica do Rio de Janeiro num período de cem anos, momento de afirmação da psiquiatria como profissão e dispositivo de poder, mostrando as resistências, conflitos e negociações em jogo neste processo.

Ou seja, a história já entrou no campo da história da loucura e psiquiatria no Brasil recorrendo à documentação clínica. Os trabalhos de Cunha e Engel compartilham com trabalhos seminais de fins dos anos 1970, produzidos fora do campo acadêmico da história, a perspectiva de crítica e denúncia do modelo asilar, mas também a percepção que assimila a ciência, no caso a psiquiatria, à ideologia. Mas devem ser entendidos no bojo de uma renovação, da influência de certa leitura de Foucault casada com um marxismo thompsoniano. A história social "vista de baixo" chega ao mundo acadêmico

\footnotetext{
${ }^{6}$ Referimo-nos aqui, obviamente, a trabalhos advindos diretamente do campo da história. Cunha de fato é o primeiro. Mais ainda, temos em mente os pioneiros no uso das fontes clínicas, preocupação deste texto. Trabalhos como de Roberto Machado, Jurandir Freire Costa ou mesmo Joel Birmam inauguram preocupações históricas acerca do passado da psiquiatria de extração focaultiana, mas não se tratam de estudos que partem do campo da história, o que é óbvio e ululante, mas precisa ser demarcado.
} 
brasileiro da história neste período e sua mescla com algumas leituras de Foucault produziu trabalhos fundamentais como os dois citados (RAGO, 1995). Aqui, associado a isso, um movimento historiográfico bem influente se deu nos estudos dos discursos e sensibilidades das classes populares e trabalhadoras (GOMES, 1998; ESTEVES, 1989), bem como os estudos que colocaram a temática da escravidão em outros termos. Ganhou vigor o campo da história social da cultura e das experiências das subalternidades, buscando realçar o protagonismo das camadas populares, suas lutas e resistências, negociações e adesões em relação com o Estado e as classes dominantes.

Daí, em estudos que têm como cerne a psiquiatria e a loucura, a importância de dar rosto, identidade e perfil para a população asilada, mostrando a lógica de poder, hierarquizações, exclusões e opressões que sobre ela incidiram. A importância do conceito thompsoniano de experiência deixou legado interessante. Nisso, a história da loucura e da psiquiatria seguiu o mesmo movimento do campo da história de uma maneira geral, para "baixo", para as diversas condições de subalternidade e para as representações.

Os estudos de Engel e Cunha legaram pressupostos interpretativos importantes para o campo de estudo da história da loucura e da psiquiatria no Brasil. Como vimos, muitos destes pressupostos interpretativos estavam presentes na história social e na sociologia histórica da loucura e da psiquiatria anglo-americana, ainda que esta não sejam citados por estas autoras. Um destes pressupostos, talvez o mais importante, é a noção de que o estudo da prática psiquiátrica, a partir das janelas que as narrativas clínicas representam, acaba por esclarecer crenças e valores sociais, muitas vezes até encobertos. Questionando as meta narrativas "sem sujeito" das décadas de 1970 e 1960, tais estudos primaram por dar rosto e identidade aos "sujeitos da loucura". Ou, ainda, resgatando Benjamin, e consoante com a citação de Hartog que abre este artigo, propugnaram o resgate dos "vencidos" e das suas lutas (BENJAMIN, 1994).

No entanto, para uma historiografia mais recente, o saber-poder psiquiátrico, nas suas faces disciplinadoras, assistenciais e científicas, não é 
capaz de anular enfrentamentos e negociações de natureza variada. Trabalhos como os de Cristiana Facchinetti, tendo por inspiração a reflexão sobre os registros clínicos do Hospital Nacional de Alienados (Rio de Janeiro) articulou a noção de "cartografia das práticas psiquiátricas" (FACCHINETTI, 2008, p.232) para retomar a face de normatização da psiquiatria, mas com ênfase nos seus rótulos diagnósticos e "disciplinas terapêuticas". Nesta chave, as fontes clínicas permitiriam visualizar situações concretas da interação psiquiatrapaciente e as transformações diagnósticas, como, por exemplo, a substituição do diagnóstico de histeria pelo de psicose maníaco-depressiva no Rio de Janeiro do início do século XX em razão da relativa hegemonização de concepções de cunho mais organicistas na psiquiatria brasileira, fato que, todavia, não modificou as práticas e percepções médicas com relação a comportamentos femininos tidos como desviantes (FACCHINETTI e CUPELLO, 2012).

A perspectiva micro-histórica também influenciou uma guinada rumo aos pacientes, cujas vozes e estratégias de vida puderam ser acessadas pela documentação clínica e seus anexos, como os escritos dos mesmos, ajuntados as suas observações. As investigações inovadoras da historiadora Yonissa Wadi (WADI, 2002) têm mostrado outras potencialidades das fontes clínicas, principalmente quando casadas com os "escritos de si”. Articulando também as leituras do chamado "último Foucault", do estudo dos processos de subjetivação, Wadi tem pensado nos diferentes processos de constituição do sujeito em condição de internamento e, portanto, em meio aos regimes de poder e verdade inerentes a tal contexto. Em alguma medida, seria possível apreender aspectos das leituras que os sujeitos da loucura teciam de si, ou, pelo menos, como a psiquiatria operou com tais leituras. Wadi vem demarcando bem o quanto as narrativas da internação mostram vivências de outro modo inacessíveis, outras óticas sobre as instituições psiquiátricas e os limites do saber-poder psiquiátrico (WADI, 2011).

O estudo de casos clínicos específicos e substanciosos passou a ser uma opção metodológica relevante. Neles, utilizando-se as observações clínicas e documentação complementar, enfatizaram-se os o enredamentos de discursos 
médicos, jurídicos, policiais, jornalísticos e dos próprios pacientes e familiares (Dias, 2017; Muñoz, 2010); a forma como se expressam os "loucos" em conjunturas político-sociais específicas (CASSÍLIA, 2011); as redes, negociações e lógicas sociais que condicionam os internamentos (RIBEIRO, 2016); as diferenças na experiência de internamento entre homens e mulheres e a obsessão psiquiátrica pela esfera da sexualidade (ENGEL, 2000 e 2008; VACARO, 2011); estudos das controvérsias e problemáticas da ciência psiquiátrica, suas transformações conceituais e as recepções de teorias e conceitos (DIAS, 2017; FACCHINETTI e CUPELLO, 2012; MUÑOZ, 2010), entre outras possibilidades.

No campo da antropologia, alguns estudos recorreram senão a livros de observações clínicas como fonte, mas a laudos periciais. É o caso do estudo de Sérgio Carrara, sobre o surgimento do Manicômio Judiciário do Rio de Janeiro. Estudando alguns casos emblemáticos que relacionaram crime e loucura, Carrara (1998) sinalizou para a importância da psiquiatria no imaginário social que aproxima as duas ordens de fenômenos. Outros trabalhos de historiadores também se debruçaram sobre laudos, buscando elucidar aspectos diversos da relação crime, psiquiatria e loucura no Brasil. A investigação da experiência e trajetórias de "loucos criminosos", enredados pelos saberes psiquiátricos, tem permitido perceber alguns influxos culturais sobre a prática psiquiátrica e mesmo as tensões inerentes aos processos de elaboração diagnóstica de pacientes que cometeram crimes (DIAS, 2017). Tais documentos têm possibilitado compreender também a recepção da "agenda biodeterminista" no Brasil, centrando-se na circulação e usos práticos destes saberes em meios institucionais dos grandes centros urbanos (FERLA, 2009).

São bastante plurais, em termos de recortes e objetos, os estudos que, ainda mais recentemente, vêm se sustentando na base empírica representada pelos registros clínicos. Sobre o período Imperial, destacam-se os estudos de Daniele Ribeiro (2015 e 2016) sobre o Hospício de Pedro II no Rio de Janeiro. A partir dos "registros de internação", entre 1847 e 1889, tem focado o funcionamento da instituição e suas relações com o "entorno social", 
ressaltando seu caráter "hierarquizante", permeado por negociações e interesses diversos. A historiadora vem sinalizando como esta instituição foi terreno de confluência de vários atores e interesses, com em acordos, alianças e conflitos. Reescrevendo a história da instituição imperial, apontou como ela recebia pessoas de vários segmentos sociais, mas, internamente, operava distinções, a depender não só da renda dos pacientes, mas também de suas relações e status. A "lógica clientelar" própria do período imperial era importante no acesso ao hospício.

A relação entre espiritismo e psiquiatria também tem sido explorada a partir de fontes clínicas. Jabert (2008) investigou as terapêuticas e os saberes kardecista da loucura no Brasil da primeira metade do século XX, com ênfase nos registros clínico do Sanatório Espírita de Uberaba, em Minas Gerais. O autor mostrou como se mesclavam ideias espiritas e psiquiátrica naquela instituição; percebeu também o protagonismo das famílias no internamento dos pacientes daquela instituição. Estudo muito inicial, mas revelando também colaboração entre espiritismo e psiquiatria, foi feito na documentação clínica, aparentemente muito promissora e rica, do Hospital Espírita de Psiquiatria Bom Retiro, no Paraná (LIMA, 2011).

Estudos com enfoque de gênero também têm recorrido aos registros clínicos. O trabalho de Pedro Muñoz, a partir da investigação aprofundada e multidimensional de um único caso, relacionou gênero e prática psiquiátrica, incursionando e perseguindo o desenvolvimento histórico da categoria diagnóstica "degeneração atípica" (MUÑOZ, 2010). Outros trabalhos mantiveram-se fiéis ao enfoque "assimétrico" mais tradicional, situando experiências e histórias de vida de um conjunto amplo de mulheres na chave do internamento dos "comportamentos femininos desviantes" (VACARO, 2011). No estudo do internamento de mulheres em instituições psiquiátricas de um passado mais recente, também recorrendo a fontes clínicas, a chave interpretativa do controle social tem se mostrado válida. É o caso de estudo que salienta os aspectos repressores e segregadores da psiquiatria capixaba dos anos 1950 (PERINI, 2013). 


\section{Considerações Finais}

Como fontes polifônicas, na qual se encerram discursos diversos, os registros clínicos emolduram a realidade social da qual fizeram parte; expressam, no dizer de Koselleck (2006, p.308), as "experiências vivas e as expectativas" de homens e mulheres no tecido do tempo. Expressões que iluminam "capacidade de observabilidade prática dos atores-autores através dos argumentos que lhe são próprios" (GUILHAUMOU, 2004, p. 52).

Dito isso, cabe enfatizar que o uso fontes clínicas para a construção de conhecimento histórico sobre a "loucura" e os saberes e práticas que a tomam como objeto tem mostrado o quanto as instituições psiquiátricas são instituições multidimensionais. As faces disciplinares e normatizadoras da prática psiquiátrica ficam relativizadas, mas não desaparecem. Salta aos olhos a heterogeneidade dos seus saberes e práticas implementadas nessas realidades institucionais. O caráter polifônico dessas fontes tem iluminado, além do que foi dito, as ignoradas intenções, visões de mundo e sensibilidades de psiquiatras e pacientes.

No que diz respeito a perspectivas de estudo, é bom mencionar a importância de recorrer a ferramentas teóricas e metodológicas de outras áreas do conhecimento, ainda mais tendo em consideração os escritos dos pacientes. Trabalhar com estas fontes requer, a "incorporação de ferramentas hermenêuticas de características interdisciplinares" (HUERTAS, 2013, p.2). A investigação da escrita do sujeito da loucura tem identificado a não aceitação sistemática, por parte destes, da condição do internamento. Como articulou Phillipe Artières (2006), o historiador deve meditar sobre o porquê destes "internados" escreverem, ou mesmo nos modos de construção de uma cultura escritas nas instituições e confinamento, marcada por súplicas, resistências, adesões e negociações.

A antropologia e a sociologia histórica das doenças podem contribuir decisivamente com suas ferramentas interpretativas (HERZLICH e ADAM, 
2001). Nunca é demais lembrar que o sujeito humano é um "complexo histórico sui generis" que expressa a cultura de seu meio social imediato de modo específico e em função de dinâmicas intersubjetivas complexas (SAHLINS, 2006). Outra perspectiva interessante advém da história e filosofia das ciências. Ian Hacking (2004) tem refletido sobre o papel do diagnóstico na criação de realidades e na interação dos sujeitos humanos classificados com estes diagnósticos. Esta guinada teórica complexifica a ideia de construção social da loucura, caras aos estudos de inspiração foucaultiana e os que combinam esta inspiração como as premissas da história social e cultural.

Vale tocar, ainda, num horizonte ainda mais rico. As fontes clínicas têm sido pensadas como fundamentais para a construção de uma história cultural das subjetividades. Os saberes médico-psicológicos, no geral, e a psiquiatria em particular, são pensados, nesta perspectiva, pelas incursões que realizam da vida subjetiva. Como discurso próprio da modernidade, da cultura do self e do pensar sobre a interioridade, sua prática traz vestígios para pensar o processo de individualização e de construção do sujeito moderno e da contemporaneidade.

Por fim, lembro o quão inestimável é o valor desses documentos clínicos como patrimônio científico, histórico e cultural. Para os estudiosos da história dos saberes e práticas psiquiátricas e das experiências da loucura, a luta por sua preservação está na ordem do dia, sobretudo no Brasil do momento presente. Momento marcado por perdas de direitos - inclusive o direito à memória - e por ataques sistemáticos que visam a deslegitimação do discurso da história como saber científico, acadêmico e escolar, mas, acima de tudo, como um conhecimento compromissado eticamente com a luta contra os fascismos, as discriminações e as marginalizações de todas as naturezas.

\section{Referências}

ARCHIBAL, M. Case records. In: SCULL, A (org.). Cultural Sociology of Mental Illnes. An A-to-Z guides (vol.1). San Diego: Sage Publications, 2013, p. 102-104.

ARTIÉRES, P. What criminals think about criminology. French Criminals and Criminological Knowledge at the end of Nineteenth Century. In: BECKER, P.; WETZELL, R. Criminals and their scientists: the history of criminology in international perspective. Washington D.C: Cambridge University Press, 2006. 
BENJAMIN, W. Magia e técnica, arte e política. São Paulo: Brasiliense, 1994.

BEVERIDGE, A. Madness in Victorin Edinburgh: a study of patients admitted to Royal Edinburgh Asylum under Thomas Clouston, 1873-1908. History of Psychiatry, 6, p.21-54 y 133-157, 1995.

BRASLOW, J. Mental Ills and Bodily Cures. Psychiatric Treatment in the Firt Half of Twentieth Century. Berkeley/Los Angeles/ London: University of California Press, 1997.

CARRARA, S. Crime e loucura: o aparecimento do Manicômio Judiciário na passagem do século. Rio de Janeiro: Ed UERJ; São Paulo: EdUSP, 1998.

CASSÍlIA, J. Doença mental e Estado Novo: a loucura de um tempo. Dissertação (Mestrado em História das Ciências e da Saúde) - Casa de Oswaldo Cruz/Fiocruz, Rio de Janeiro, 2011.

COLEBORNE, C. White men and weak masculinity: men in public asylums in Victoria, Australia, and New Zealand, 1860s-1900s. History of Psychiatry, V. 25, n.4, p.468-476, 2014. p. 469.

CUNHA, M. O espelho do mundo. Juquery a história de um asilo. Rio de Janeiro: Paz e Terra, 1986.

DIAS, A. Dramas de sangue e loucura: psiquiatria e crime no Rio de Janeiro (1901-1921). Rio de Janeiro: Novas Edições Acadêmicas, 2017.

DÖRRIES, A; BEDDIES, T. The Witternauer Heilstätten in Berlin: a case record study of psychiatric patients in Germany, 1919-1960. In. PORTER, R.; WHRIGHT, D. The confinement of the insane: Cambridge: Cambridge University Press, 2003, p.149-172.

DUMOLIN, L. L' expertise judiciaires dans la construction du jugement: de la ressource à la contrainte. Droit et Socièté, vol. 44-45, p.199-223, 2000.

EDLER, F. A húbris bioética: rumo a uma polícia epistemológica. Revista Brasileira de Sociologia, v.3, n.5, p.97-113, 2015.

EDLER, F. A Medicina no Brasil Imperial: clima, parasitas e patologia tropical. Rio de Janeiro: Editora FIOCRUZ, 2011.

ENGEL, M. Os Delírios da Razão: médicos, loucos e hospícios (Rio de Janeiro, 1830-1930). Rio de Janeiro: Editora Fiocruz, 2001.

ENGEL, M. Psiquiatria e feminilidade. In: PRIORE, M (org). História da Mulheres no Brasil. $3^{\text {a }}$ ed. São Paulo: Contexto, 2000.

ENGEL, M. Sexualidade interditadas: loucura e gênero masculino. História, Ciências, Saúde - Manguinhos, v. 15, 2008.

ESTEVES, M. Meninas perdidas: os populares e o cotidiano do amor no Rio de Janeiro. Rio de Janeiro: Paz e Terra. 1989.

FACCHINETTI et al. As insanas do Hospício Nacional de Alienados. História, Ciências, Saúde - Manguinhos, Rio de Janeiro, v.15, supl., p.231-242, jun. 2008.

FACCHINETTI, F; CUPELLO, P. O processo diagnóstico das psicopatas do Hospital Nacional de Alienados: entre a fisiologia e os maus costumes (19031930). Revista Estudos em Psicologia. Rio de Janeiro, v.11, n.2, 2012, p.697718. 
FERLA, L. Feios, sujos e malvados sob medida: do crime ao trabalho, a utopia médica do biodeterminismo em São Paulo (1920-1945). São Paulo: Alameda, 2009.

RIVERA-GARZA, C. La Castañeda. Narrativas dolientes desde el Manicomio General. México, 1910-1930. México D.F.: Maxi TusQuets, 2011.

GOLDBERG, A. The Eberbach Asylum and the Practice (s) of Nymphomania in Germany, 1815-1849. Journal Women History. V.9, n.4, p.35-52, 1998.

GOLDSTEIN, J. Console and Classify: The French Psychiatric Profession in the Nineteenth Century. Cambridge: Cambridge University Press, 1987.

GOMES, A. A Invenção do Trabalhismo. São Paulo: Vértice; Rio de Janeiro: IUPERJ, 1998.

GUILHAUMOU, J. La historia linguística de los conceptos: el problema de la intencionalidade. Revista Ayer, n.53 (1), p.47-61, 2004.

HACKING, I. Between Michel Foucalt and Enving Goffman: between discours in the abstract and face-to-face interaction. Economy and Society, v. 33 (3), p. 277-302, 2004.

HERZLICH, C; ADAM, P. Sociologia da doença e da medicina. Bauru - São Paulo: EDUSC, 2001.

HUERTAS, R. Another history for another psychiatry. The patient's view. Culture \& History Digital Journal, v. 2, n. 1, p. 1-11, 2013.

HUERTAS, R Historia Cultural de la Psiquiatría. Madri: Los libros de la Catarata, 2012.

JABERT, A. De médicos e médiuns: medicina, espiritismo e loucura no Brasil da primeira metade do século XX. Tese (Doutorado em História das Ciências e da Saúde) - Fundação Oswaldo Cruz, Casa de Oswaldo Cruz, 2008.

KOSELlECK, R. Futuro Passado: contribuição à semântica dos tempos históricos. Rio de Janeiro: Contraponto; Ed. PUC-Rio, 2006.

LANTERI-LAURA, G. La chronicité dans la psychiatrie moderne française. Note d'histoire théorique et sociale. Annales. Économies, Sociétés, Civilisations, $27^{\circ}$ année, n.3, p.548-568, 1972.

LIMA, A. Psiquiatria e espiritismo no atendimento à doença mental: a história do Hospital Espírita de Psiquiatria Bom Retiro (Curitiba -1930-1950). Dissertação de Mestrado. Programa de Pós-Graduação em Psicologia, 2011.

MARLAND, H. Under the shadow of maternity: birth, death and puerperal insanity in Victorian Britain. History of Psychiatry, Vol 23, n.1, 2012.

MOLINA, A. Un mesías, ladrón y paranoico en el Manicômio La Castaneda. A propósito de la importancia historiográfica de los locos. Estudios de Historia Moderna y Contemporánea de México, n. 37, p. 71-96, 2009.

MUÑOZ, P. Degeneração atípica: uma incursão ao arquivo de Elza. Dissertação (Mestrado em História das Ciências e da Saúde) - Fundação Oswaldo Cruz. Casa de Oswaldo Cruz, 2010.

NOVELLA, E. De la historia de la psiquiatría a la historia de la subjetividad. Asclépio. Vol. LXI, n. 2, julio-diciembre, p. 261-280, 2009.

PERINI, J. Hospital Adauto Botelho: controle social e mulheres. Vitória -ES. Dissertação (Mestrado em História). Universidade Federal do Espírito Santo. Espírito Santo, 2013.

POCOCK, J. Linguagens do Ideário Político. São Paulo: Edusp, 2003. 
PORTER, R.; MICALE, M. Introduction: Reflections on Psychiatry and its Histories. In. PORTER, R. and MICALE, M. Discovering the history of Psychiatry. New York/ Oxford. Oxford University Press, p.3-23, 1994.

PORTER, R. A social history of madness. A world throught the eyes of the Insane. New York: Weidenfeld \& Nicolson, 1987.

PORTER, R. The Patient's View: Doing Medical History From Below. Theory and Society, 14, 2, 1985, 175-98,

PRESTWICH, P. Female Alcoholism in Paris, 1870-1920: The Response of Psychiatrists and of Families. History of Psychiatry, v.14, n.3, p.321-336, 2003 b.

RAGO, M. Foucault: um pensamento desconcertante - o efeito-Foucault na historiografia brasileira. Tempo Social (Rev.Sociol.USP). São Paulo, 7 (1-2), pp.67-82, 1995.

RIBEIRO, D. Ciência, caridade e redes de sociabilidade: o Hospício de Pedro II em outras perspectivas. História, Ciências, Saúde - Manguinhos, v. 23, p. 1153-1167, 2016.

RIBEIRO, D. Tramas da loucura na Corte Imperial: ciência, caridade e redes de sociabilidade no Hospício de Pedro II (1883-1889). Curitiba: Editora Prismas, 2015.

ROSEN, G. Madness in Society: Chapters in the Historical Sociology of Mental Illness. Chicago: University of Chicago Press, 1968.

SACRISTÁN, C. Por el bien de la economía nacional. Trabajo terapéutico y asistencia pública en el Manicomio de La Castañeda de la ciudad de México, 1929-1932. História, Ciências, Saúde-Manguinhos, v. 12, n. 3, p. 675-92, set. 2005.

SAHLINS, M. História e Cultura: apologia a Tucídides. Rio de Janeiro: Jorge Zahar Ed., 2006.

SALLA, F; BORGES, V. Prontuários de instituições de confinamento. In. RODRIGUES, R. Possibilidades de pesquisa em História. São Paulo: Contexto, 2017, p.115-136.

SCULL, A. Museums of Madness: the social organization of insanity in nineteenth-century England. London: Allen Lane, 1979.

SCULL, A. The insanity of place/the place of insanity: essays on the history of psychiatry. New York, Routledge, 2006.

SHOWALTER, E. The Female Malady: Women, Madness and English Culture, 1830-1980. London: Virago, 1987.

TOMES, N. Feminist Histories of Psychiatry. In: PORTER, R. and MICAELE, M. S. Discovering the history of Psychiatry. New York/ Oxford: Oxford University Press, 1994, 231-262.

VACARO, J. A Construção do Moderno e da Loucura: Mulheres no Sanatório Pinel de Pirituba (1929-1944). Dissertação (Mestrado em História Social). Universidade de São Paulo, Departamento de História. São Paulo, 2011.

WADI, Y.M. Palácio para guardar doidos: uma história das lutas pela construção do hospital de alienados e da psiquiatria no Rio Grande do Sul. Porto Alegre: Ed. UFRGS, 2002. 
WADI, Y.M. Entre muros: os loucos contam o hospício. Topoi (Rio de Janeiro), v. 12, p. 250-269, 2011.

Recebido em: 12 de dezembro de 2018 Aceito em: 15 de abril de 2020 